\title{
Disaggregated Short-Term Inflation Forecast (STIF) for Monetary Policy Decision in Sierra Leone
}

\author{
Emerson Abraham Jackson, ORCID: https://orcid.org/0000-0002-2802-6152 \\ Research Economist, Model Building and Analysis Section, Bank of Sierra Leone, Sierra Leone, West \\ Africa
}

\section{Edmund Tamuke}

Research Economist, Model Building and Analysis Section, Bank of Sierra Leone, Sierra Leone, West Africa

\section{Mohamed Jabbie}

Research Economist, Balance of Payment Analysis \& External Relations Section, Bank of Sierra Leone, Sierra Leone, West Africa

\begin{abstract}
In this paper, the researchers have developed a short-term inflation forecasting (STIF) model using BoxJenkins time series approach (ARIMA) for analysing inflation and associated risks in Sierra Leone. The model is aided with fan charts for all thirteen components, including the Headline CPI as communication tools to inform the general public about uncertainties that surround price dynamics in Sierra Leone - this then make it possible for policy makers to utilise expert judgments in a bid to stabilize the economy. The uniqueness of this paper is its interpretation of risks to each of the disaggregated components, while also improving credibility of decisions taken by policy makers at the Bank of Sierra Leone [BSL]. Empirically, Food and Non-Alcoholic Beverages, Housing and Health components indicate that shock arising from within or outside of Sierra Leone can significantly impact headline CPI, with immediate pass-through effect of high prices on consumers' spending, at least in the short-run. The outcome of this empirical research shows uniqueness of the disaggregated model in tailoring policy makers' attention towards targeting sector-specific policy interventions. Fan Charts produced have also highlighted degree of risks, which is based on confidence bands, which shows deviation from the baseline forecast. The ultimate goal is to improve sectoral productive capacity, while at the same time, monitoring price volatility spill-over through empirical disaggregation of the CPI basket - in association with this, outcome from the study also shows that the use of multivariate models like VAR would be welcome to monitor events on price dynamics in the national economy.
\end{abstract}

Keywords: STIF; ARIMA; Disaggregated CPI; Fan Charts; Sierra Leone.

JEL Classification: C13, C52, C53, E37.

Cite as: Jackson, E.A., Tamuke E., Jabbie M. (2019). Disaggregated Short-Term Inflation Forecast (STIF) for Monetary Policy Decision in Sierra Leone. Financial Markets, Institutions and Risks, 3(4), 32-48. http://doi.org/ 10.21272/ fmir.3(4). 32-48.2019

(c) The Authors, 2019. This article is published with open access at Sumy State University.

\section{Introduction}

Price stability is, if not among others, one of the core objectives of central banks around the world, particularly in ensuring monetary policy decisions are targeted appropriately to minimise burden on economic agents' wellbeing (King, 2005 and Mwenese and Kwizera, 2018). This is very key as stabilisation of prices are critical for investments and, in controlling the value of local currency against international currencies. In this vein, management at the Bank of Sierra Leone is continually demonstrating commitments to ensuring its mandate on price stabilisation is robustly addressed through empirical research undertakings carried out by staff in the research and other policy-oriented departments.

Price stabilisation is very much a stochastic process given its dependence on various macroeconomic components, which on many occasions, can be determined by economic agents' persistent habit formation. During periods of inflationary pressure, there is high risk of a country not being able to compete internationally, which also add pressure on central government finances. As exemplified by Mordi et al (2012), there is a risk 
Financial Markets, Institutions and Risks, Volume 3, Issue 4, 2019 ISSN (online) - 2521-1242 ISSN (print) - 2521-1250

for balance of trade to worsen, with a likely negative impact on exchange rate dynamics and reduction in export earnings, which ultimately result in high fiscal deficit (Jackson and Jabbie, forthcoming).

The occurrence of a volatile inflation is common to free market enterprise system and more acutely felt in an environment with high inflation speculation, which may arise as a result of market failure and the continued lack of confidence in an economic system (Coleman, 2007; Jackson, 2018; Jackson and Tamuke, 2018; Jackson and Jabbie, 2019). In order to address the state of inflation in an economy, almost or nearly all economic think-tank institutions have resorted to some form of empirical research venture in predicting future outcomes of inflation in a bid to developing strategy or policy geared towards maintaining a balanced economic state of affairs in support of decent well-being for citizens.

Forecasting macroeconomic indicators, especially inflation, provide interested economic agents with the requisite information about future trends of these indicators to plan and rationalise economic decisions in a coherent and organized manner. As noted by Hendry and Hubrich (2006), projections of macroeconomic aggregates are not only utilised by central banks for policy making, but also very important to facilitate private sector investments, while also serving as a guide government in the direction on policies relating to spending and sectoral investments. The importance of forecast is been resounded all around the globe, given its relevance in addressing the dynamics of macroeconomic variables and their significant implications for economic stabilisation and decision-making.

Because of the relevance of macroeconomic projections, focus has now been renewed and directed towards disaggregation forecasting; this is done by forecasting component indices and aggregates rather than just the composite index (Hendry and Hubrich, 2006). Theoretically, it is believed that the disaggregated approach improve forecast accuracy relative to aggregate forecasting, provided the data generation process is trustworthy (Hendry and Hubrich, 2006; and Mercellino, Stock and Watson, 2003). Disaggregated forecast using ARIMA has proved very reliable for predicting short-term inflation outcome by highly rated institutions like the Bank of England, European Union and the Federal Reserve Board.

\section{Significance of the Paper and Emerging Knowledge}

Over the years, researchers at the BSL in particular and elsewhere (in the academia and independent institutions both at national and international level) have dedicated efforts in applying both univariate and multivariate econometric tools to inform policy decisions about the direction and persistence of inflation in the country using aggregated CPI data (Bangura et al, 2012; Kallon, 1994; Jackson et al, 2018; Jackson and Tamuke, 2018; Tamuke, Jackson and Sillah, 2018).

In view of the BSL's earlier focus on monetary aggregate targeting, the effort since 2011 has been directed at ensuring price stability is set at the heart of future approach to effective economic management, while also setting eyes on stabilising the financial system as addressed in the new BSL and Banking Acts of 2019. In this regard, it is essential that effort is championed towards addressing inflation persistence in the economy as mandated by the BSL, which is focused on price stabilisation. The use of a Short Term Inflation Forecast (STIF) tool like ARIMA is one of the most robust means of addressing inflation dynamics and expectations over the monetary policy period in an economy (Box and Jenkins, 1976; Jackson and Tamuke, 2018); at the BSL, the Box-Jenkins ARIMA model is one of the most commonly used time series methodology applied by staff to support monetary policy decisions, particularly in the short term.

In terms of the focus on emerging knowledge and motivation, the use of STIF in this study is aimed at providing inflation forecast for each of the disaggregated components, while also taking cognisance of uncertainties surrounding inflation dynamics with the use of Fan Charts. It is believed that this study will provide possible answer to question pertaining to "which component in the CPI basket poses the most risk in stabilising price dynamics in the Sierra Leone economy'. On this note, the study will identify suitable confidence bands on which policy decisions can be directed in a bid to addressing persistently high inflation and expectations in the economy, while also paying particular attention to those components, which seem to pose the most risks.

\section{Objectives}

This paper, has made its objective focus by ensuring:

That contribution to emerging knowledge of disaggregated inflation forecasting in Sierra Leone is brought to the fore by addressing uncertainties (using Fan Charts) that surround each of the disaggregated components in the Consumer Price Index (CPI) basket [taking cognisance of weights attached to components and their long terms impact on the overall inflation outcome]. 
$>$ Also, ensuring policy recommendations are directed at steering MPC deliberation(s) towards the application of diverse methodologies aimed at unearthing on-going concerns around the sporadic nature of inflation in the country.

\section{Structure of the Paper}

Going forward, the remaining sections of the paper is divided as follows: Section two provide an overview of recent inflation trends in Sierra Leone. Section three provide a short review of theoretical and empirical literatures. Section four addresses the methodology, which incorporate data collection and usage, model specification and technique(s) of analysis. Section five present and discusses empirical findings, which include the out-of-sample forecasts [the ARIMA program codes approach] and fan charts for communicating uncertainties in support of effective policy deliberations (See Jackson and Tamuke, 2019 for varied application). Section six conclude the paper with suggestions for future policy directions of inflation control / management in Sierra Leone.

\section{Overview of Recent Inflation Trends in Sierra Leone}

Inflation and its sporadic nature have been a topical concern in Sierra Leone for decades, and more so in view of its heightened hike above the revised $18 \%$ target set by MPC in the second half of 2018. In order to process future outlook of inflation, which is used by the MPC for policy deliberation, researchers in the research department have resort to utilising historical data compiled by Statistics Sierra Leone (SSL), weighted on their influence to economic agents' persistent habit as shown in Table 1.

Table 1. Classification of Individual Consumption by Purpose (COICOP) for Sierra Leone as at December 2018

\begin{tabular}{|l|c|}
\hline \multicolumn{1}{|c|}{ CPI Disaggregated Items } & Weight (\%) \\
\hline Food \&Non-Alcoholic Bev. & 43.18 \\
\hline Alcoholic Beverages, Tobacco and Narcotics & 2.33 \\
\hline Clothing and Footwear & 7.73 \\
\hline Housing, Water, Electricity, Gas and Other Fuels & 13.60 \\
\hline Furniture, Household Equipment and Household Maintenance & 4.19 \\
\hline Health & 12.63 \\
\hline Transport & 4.72 \\
\hline Communication & 2.05 \\
\hline Recreation and Culture & 1.34 \\
\hline Education & 3.06 \\
\hline Restaurant and Hotels & 1.12 \\
\hline Miscellaneous Goods and Services & 4.05 \\
\hline Total weight & 100 \\
\hline
\end{tabular}

Source of Information: SSL CPI Press Release, December 2018.

In terms of weights and the overall contribution to CPI in Sierra Leone as indicated in Table 1, three disaggregated components, namely "Food \&Non-Alcoholic Bev. (currently weighing 43.18\%); Housing, Water, Electricity, Gas and Other Fuels (currently weighing 13.60\%); and Health (currently weighing 12.63\%)" are the highest contributors in the basket as published by Statistics Sierra Leone in its December 2018 CPI release. In summary, this indicate that, as at the time of the published weights, these three components were the most volatile influences in the overall CPI basket.

In order to address the sporadic outburst, MPC deliberations as at the end of 2018Q4 targeted policies to address the situation. With the continued influence of externalities like shocks to the petroleum industry and coupled with exchange rate fluctuations attributed to persistent weaknesses inherent in the country's real sector, it has been a real challenge for authorities to get firm grip of the expected downward trend of inflation. Charts 1 and 2 below provide an outlook of the pendulistic state of inflation over the years with influential force like exchange rate. 


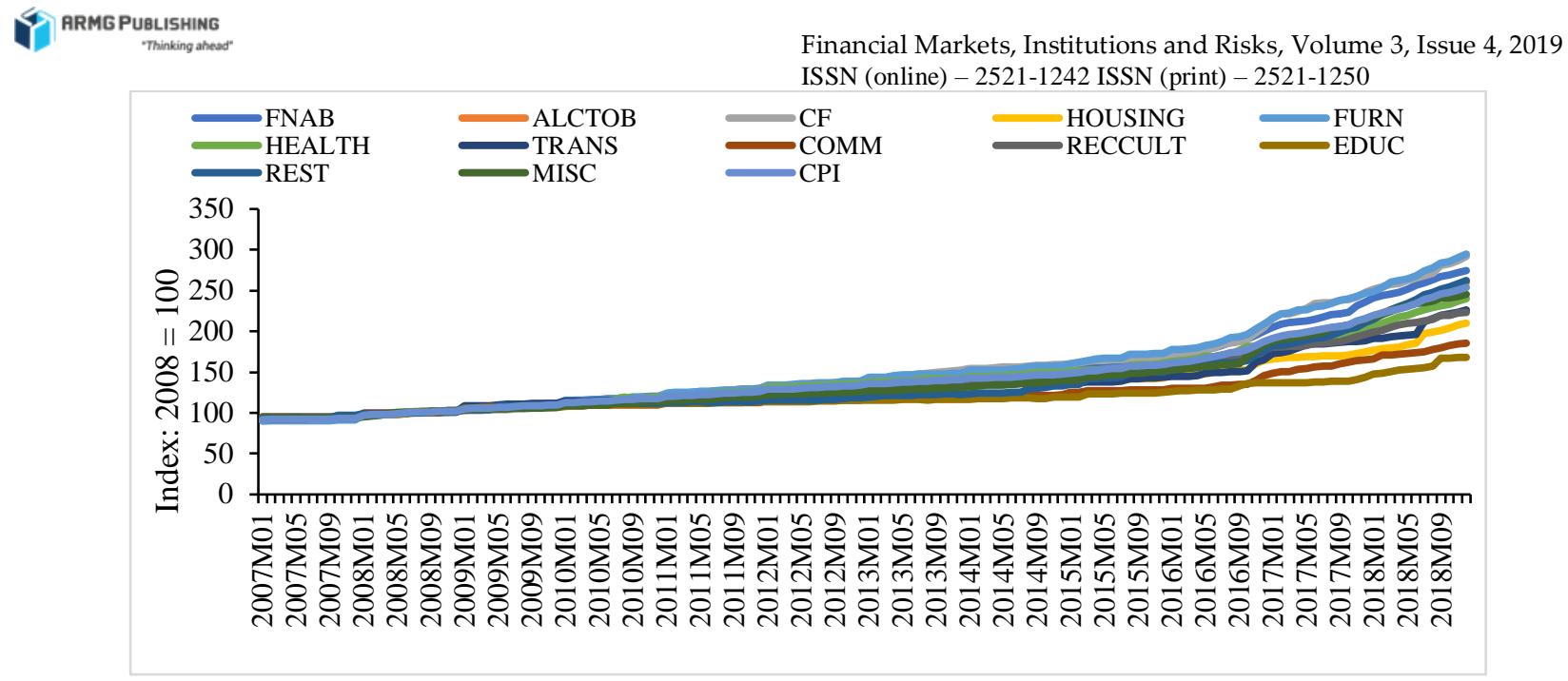

Figure 1. Trend of Inflation in Sierra Leone [2007 M01 - 2018 M12]

Source: Statistics Sierra Leone.

Figure 1 typify inflation dynamics of the CPI disaggregated basket between 2007M01 - 2018M12. The disaggregated basket is a real attestation of the historical direction of inflation in Sierra Leone, which shows a "fan-out" look of the CPI disaggregated basket from 2009M01 to 2018Q4. Several empirical research outputs have shown the macro-level influences of structural problems like exchange rate pass-through and also, the legacy of fiscal indiscipline the country experienced between 2017-18, which invariably has given rise to the country's present state of high inflationary pressure (Bangura et al, 2012; Mansaray-Pearce Liu, 2015; Jackson and Tamuke, 2018; Jackson Jabbie and Tamuke, forthcoming; Jackson and Jabbie, forthcoming). Based on Figure 1, components like Transport and alcohol and tobacco recorded high impact on the overall inflation than the headline CPI itself. This is as no surprise given the poor performance of the real sector, which has paved the way for higher level imports to meet demand for local consumption.

In view of the above discussion about the historical state of inflation in Sierra Leone, Figure 2 below shows that inflation is largely driven by movements in exchange rate. The greatest impact of inflation was felt around the later part of 2015, which is indicative of the twin crisis shock of Ebola and commodity price slump experienced in the country. With the weak state of the real sector and also coupled with the shocks, this has manifested itself in a direct pass-through to high price movements in the country's commodity market, except more recently in the last quarter of 2018 which witnessed a disinflation of almost above one-percent rate.

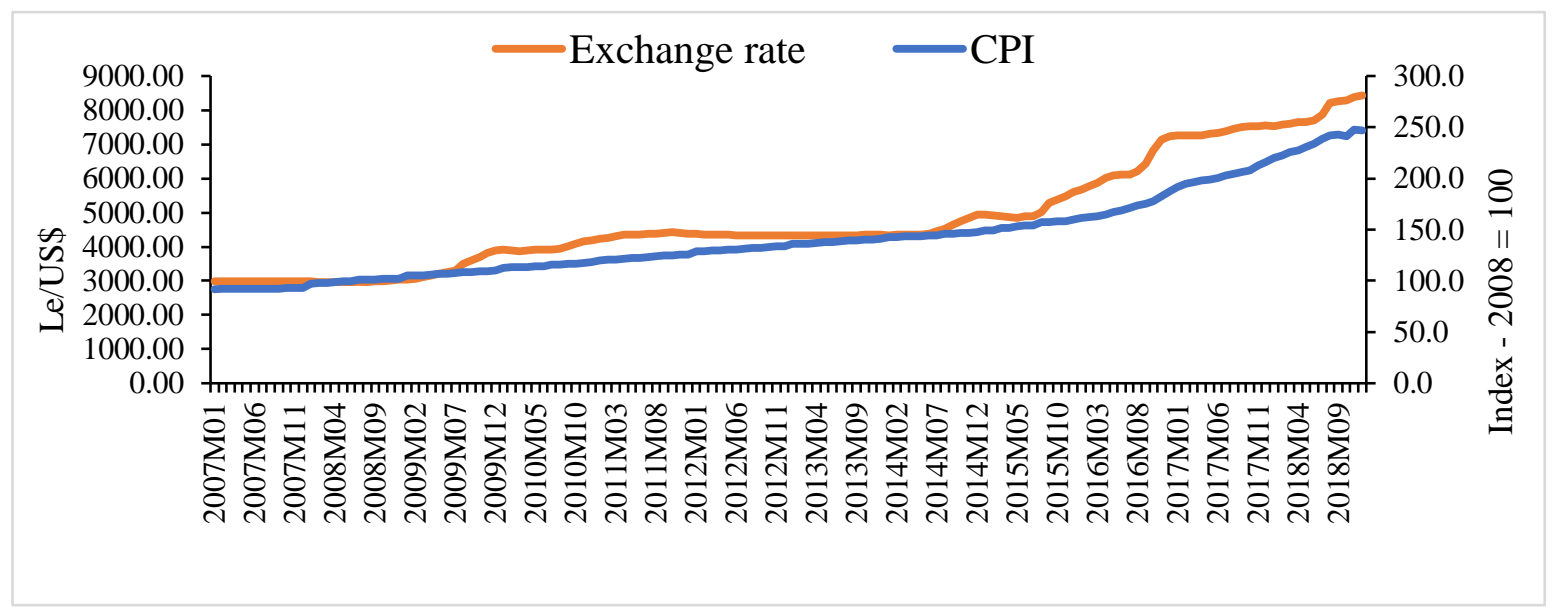

Figure 2. Inflation Charted with Exchange Rate [2007M01 - 2018M12]

Source: EVIEW Output.

\section{Literature Review}

3.1. Theoretical Review. Inflation dynamics and forecast is a topical concern around the world, particularly for central banks as it is one of the ways in which authorities can judiciously utilise resources [for example, 
Financial Markets, Institutions and Risks, Volume 3, Issue 4, 2019

ISSN (online) - 2521-1242 ISSN (print) - 2521-1250

professional staff knowledge and data] by engaging in empirical research needed to set realistic policy measures in a bid to achieving prescribed inflationary target(s). In the developed economies, inflation can be broadly perceived as a cause of money supply growth, while the situation in developing economies is a contrast, with factors normally attributed to high fiscal imbalance and exchange rate depreciation surfacing highly (Totonchi, 2011; Sergent \& Wallace, 1981; and Montiel, 1989).

Theoretically, research tasks commissioned by various researchers have grouped the sources of inflation using six-block analogy; monetary shocks, Demand side, supply-side (or real) shocks, structural and political factors or the role of institutions (Totonchi, 2011; Humphrey, 1998; Sims, 1980; and Gordon, 1977). This typically indicate that inflation can be a predominant factor of macroeconomic and institutional occurrences, which then makes it very difficult for institutions like the BSL, in particular, to get firm grip of its up-swing cycle in satisfying decent living standard for economic agents in the Sierra Leone economy. In order to address concerns around the above sources / causes of inflationary movements, many central banks across the world have and are continuously commissioning empirical research endeavours using historical data (both univariate and multiple) and also, inflation expectation surveys to address the underlying causes of inflation.

According to Lim and Papi (1997: 7), the public finance approach in explaining inflationary pressure also emphasised that, given the limits on domestic and foreign borrowing as dictated by financial market conditions and solvency requirements, monetisation is the residual form of deficit financing. Rodrik (1991) noted that in the 1980s, the consequences of a given finance deficit were further aggravated by a decline in the demand for money-base, due partly to relaxation of foreign exchange regulations, which then resulted in portfolio reallocation towards foreign currency; a situation currently experienced in the Sierra Leone economy, for which the dollar currency seem to be the dominant factor in almost all sectoral dealings / transactions.

Rodrik (ibid) went further to argue that fiscal deficit is also affected by political influence and for which public price policy has been used in this situation, by ensuring public prices are kept unchanged prior to elections and with expectation of future increase thereafter. Therefore, there is a tendency (across the globe) for prices to be adjusted at the higher end after elections because of the effects of public prices in the total price index, and, the indirect effect of public prices through private prices.

Lim and Papi (1997: 8) noted in their study that structural and cost-push factors during inflationary process can be explained by (i) the link between exchange rate and prices; (ii) the mark-up on final product prices on account of oligopolistic industrial structure; and (iii) wage pressures stemming from indexation rules and deeprooted inflationary pressures. Equally, Rodrik (1991) demonstrated that rising inflation and continued devaluation of the country's Lira in the 1980s gave rise to the hypothesis of 'devaluation-inflation' spiral. This can be attributed to high dependence on importation of capital and intermediary goods, normally dominated by oligopolistic industrial structures that allow a mark-up over costs by manufacturing firms.

3.2. Empirical Review. The use of ARIMA has proved very popular in terms of its reliability to address short term inflation forecast in a county. To prove this, empirical research conducted over the years by researchers at the BSL and elsewhere (for example, in other central banks and the academia) have shown that inflation is very well tracked with both univariate and exogenous component (ARIMAX) to address external influences of the direction of inflation in a country over a given period of time (Jackson, 2018; Jackson et al, 2018; Jackson and Tamuke, 2018; Bangura et al, 2012 and Kallon, 1994).

Specific to addressing risks associated with univariate inflation forecast, Jackson and Tamuke (2018 and forthcoming) made attempt in their research to address risks associated with forecast outcome from the composite headline CPI for Sierra Leone. Despite the fact that the study was not able to unearth the source(s) of risks emanating from hike in a disaggregated CPI basket, it was able to address specific risks using specified confidence bands, which was explained around the upper and lower bands in support of MPC decision on rate fixing.

As the need to explore inflation dynamics intensify for many countries, particularly for central banks, where price stability / inflation targeting is set as core objective, the use of disaggregated study seem to be taking a central focus as a way of increasing forecast accuracy, which is mostly complemented with Fan Chart analysis of associated risks around specified confidence bands. Espasa et al (2002) made use of cointegration analysis to evaluate sources of non-stationarity in data used; their study revealed trending behaviour in the identified components, which then allowed them to conclude that a disaggregated estimation could prove more accurate 
Financial Markets, Institutions and Risks, Volume 3, Issue 4, 2019 ISSN (online) - 2521-1242 ISSN (print) - 2521-1250

in forecasts. Their approach of univariate models out-performed the multivariate study in terms of forecast accuracy than the more commonly used aggregated estimation approach to short and medium term processes.

Different empirical research outcomes seem to have produced mixed results in terms of the application of appropriate approach, which meant either aggregate or disaggregate forecast can prove accurate for policy decision, depending on the focus of the research. To address such mixed outcomes, Hubrich (2005) used different AR and VAR specifications for the Euro area. In this study, she observed that none of the two outcome out-perform a random walk on a twelve-monthly horizon. On a similar outcome, Benalal et al (2004) made use of different univariate and multivariate specifications and in this, it was proved that direct forecast of aggregate CPI outperform the disaggregated component approach for period more than twelve months, while at the same time, mixed results were witnessed for shorter periods of less than twelve months.

Harvey (2012) also revealed some peculiarity about the behaviour of disaggregated outcomes from univariate forecast of inflation study. The results from his study shows that direct forecasts of aggregate inflation outperform aggregate forecasts derived from aggregating forecasts from the subcomponents for all the steps of the forecasts. The study shows that adding information from the subcomponents also has the tendency of improving direct forecast of aggregate series for 1-step-ahead. The result also shows that for 6-stepahead and 12-step-ahead forecasts, direct univariate forecasts are superior to forecasts from all the models.

Similar to the focus of this study, Mordi et al. (2012) made use of STIF approach to forecast inflation, with associated risks outputted from Fan Charts for each identified component; their study revealed that disaggregated forecast approach can provide a more accurate means for policy decisions, where risks are identified based on a given confidence bands. Given the stochastic nature of data used, outcomes from empirical studies around inflation forecast and associated risks can help researchers explore different outcomes on how data can respond to apriori expectations, while the underlying focus is to serve its purpose of addressing core policy decisions in maintaining price stability as in the case with the BSL.

\section{Methodology}

4.1. Technique of Analysis. The main aim of this paper is to model STIF for Sierra Leone using disaggregated components for CPI, which follows a robust autoregressive process of Box-Jenkins (univariate) Time-Series approach; the weight of components are also taken into consideration so as to factor their influence in the inflation forecast dynamics for the overall CPI basket. The importance of this technique is its benefit of modelling disaggregated components of the CPI basket, which is new to supporting monetary policy decision in the Sierra Leone economy.

This is based on the application of Structural Time-Series Model (STSM, similarly applied by applied by Mordi et al; 2012; Mwenese and Kwizera 2018), expressed in the generic form as: $\pi_{t}=\chi_{t}+\theta_{t}+v_{t}+\varepsilon_{t} \quad \varepsilon_{t} \approx \mathrm{N}\left(\mathrm{O}, \sigma_{\varepsilon}^{2}\right)$

where the dependent variable ${ }^{\pi_{t}}$, is expressed as summation of all components:

series $_{t}=$ trend $_{t}+$ cycle $_{t}+$ autoregressive $_{t}+$ irregular $_{t}$

Individual component can equally be modelled as a State-Space, with the recursive solution algorithm in Kalman filter (Rummel, 2011 and Mordi et al, 2012).

The trend is modelled as: $\chi_{t}=\chi_{t-1}+\tau_{t}+\eta_{t} \quad \eta_{t} \approx N\left(0, \sigma_{\eta}^{2}\right)$

where $\tau_{t}=\tau_{t-1}+\varsigma_{t} \quad \varsigma_{t} \approx \mathrm{N}\left(0, \sigma_{\mathrm{s}}^{2}\right)$

The cycle as expressed by Harvey and Jaeger (1993) and also by Mordi et al. (2012) is modelled as:

$\left[\begin{array}{c}\Theta_{t} \\ \Theta_{t}^{*}\end{array}\right]=\rho_{\theta}\left[\begin{array}{cc}\cos \left(\lambda_{c}\right) & \sin \left(\lambda_{\mathrm{c}}\right) \\ -\sin \left(\lambda_{c}\right) & \cos \left(\lambda_{\mathrm{c}}\right)\end{array}\right]\left[\begin{array}{c}\Theta_{t} \\ \Theta_{\mathrm{t}-1}^{*}\end{array}\right]+\left[\begin{array}{c}\mathbf{K}_{t} \\ \mathbf{K}_{t}^{*}\end{array}\right] \mathrm{t}=1, \ldots, \mathrm{T}$

where $\mathrm{K}_{t}, \mathrm{~K}_{t}^{*} \approx \mathrm{N}\left(0, \sigma_{\mathrm{K}}^{2}\right)$

The autoregressive component can be expressed as: $\mathbf{v}_{t}=\rho_{v} v_{t-1}+\xi_{t} \quad \xi_{t} \approx N\left(0, \sigma_{\xi}^{2}\right)$

Components in the disaggregated CPI basket for this study also follows an autoregressive process expressed in the form of $\mathrm{p}$ lags (AR (p)), with varying $\mathrm{p}$ values for each component, determined from general to a more 
Financial Markets, Institutions and Risks, Volume 3, Issue 4, 2019

ISSN (online) - 2521-1242 ISSN (print) - 2521-1250

specific approach. The estimation process is achieved through an AR model, with embedded lag structures, significantly tested to produce best component model that describe the inter-temporal dependence, while components are thought to be exhibiting a form of simulated historical behaviour, which constitute a form of white-noise process (Salam et al, 2006 and Mordi et al, 2012).

Based on the automated codes, this study has adopted optimal estimation of AR and MA processes by specifying maximum of 12 lag specification [maxar $=12$ ] that is representative of components sampled in the CPI basket. The best model for individual components were automatically detected by specifying coded criteria that allows one of the following criteria to be selected: "Akaike Information Criterion.Change to @ schwarz or @ hq for Schwarz and Hannan-Quinn criteria". The best model for individual components exhibited a parsimonious characteristic that have mean reverting parameters, and adequately describe the data with white noise residual process, with a reliably good out-of-sample forecasts.

The advantage of the STIF framework used in this study is its informative nature of forecasts that gives credibility with the use of varying confidence band of Fan Charts, which then allow uncertainty to be unearthed. This then make it possible for associated risks to be explained convincingly for policy deliberation and eventually communicating expert decisions to the public (Prescatori and Zaman, 2011).

4.2. Data. The STIF framework for this study was based on monthly dataset comprising of 13 disaggregated CPI components for Sierra Leone, covering the period from 2007M01 to 2018M12. Table 1 shows that in order of size, the three components with weighted size are "Food \&Non-Alcoholic Bev. (43.18\%); Housing, Water, Electricity, Gas and Other Fuels (13.60\%); and Health (12.63\%)"; these in total account for $69.41 \%$ of price level in the CPI basket. The time series of the price level for the twelve components are shown in Chart 1 .

4.3. Model Specification. For the specified automated codes, each individual index has been modelled to reflect their unique feature by incorporating constant, lag structure(s), first difference and seasonal adjustment[s], typical of Rummel's (2011) and other researchers' efforts like that of Mordi et al., 2012. Specific to this research paper, the univariate Box-Jenkins model examine characteristics of each components' inflation process with a unique best equation as shown in section 5.1. The equations for the estimation were produced through an automated process as excerpted below in Table 2, by selecting the best model through several iterated processes (see in Appendix 1 for the complete codes).

Table 2: Best ARMA selection Code

\begin{tabular}{|l|}
\hline if arma_!i_!a_!m. @aic $<!$ mininfocrit then \\
\hline !besta $=$ !a \\
\hline !bestm $=$ !m \\
\hline !mininfocrit $=$ arma_!i_!a_!m. @ aic \\
\hline Endif
\end{tabular}

Source: Model Iteration Code from EVIEWS [see Appendix 1].

\section{Empirical Results}

5.1. Estimation using Disaggregated ARIMA Code [Regression Test Outcomes]. With reference to Appendix 2, each estimation has followed the normal econometrics approach of a regression output, with estimated outputs for the out-of-sample forecast period periods (2019M01-2019M09) showing less than 50\% of strong $\mathrm{R}^{2}$ values. This is due to the fact that the automated model was developed to output at either level or first difference; uniquely, all outputs have satisfied basic statistical test characteristics like the Durbin-Watson statistics, with values ranging between 0 and 2. The inverted AR and MA Root values also ranged between 0 and 0.99, which is an indication of a successful unit root criteria being satisfied. Incorporated Automated features meant that the best models were outputted with reasonably low SC and AIC values as well.

The interpretation of 'Residual, Actual and Fitted lines' shows that adjusting for seasonality have made it possible for the Fitted lines [as depicted on the blue staggered lines in Appendix 2] in all components to exhibit minimal volatility in the data when compared to the actuals [as depicted on the blue lines]. The graphs also show that all components are stationary at difference. The stability of the model was also confirmed as shown for all the best models in Appendix 2.

5.2. Disaggregated Components Forecast. This section provides an indication of individual out-of-sample forecast for all 13 components in the CPI basket. Figure 3 and Appendix 3 for forecast results for individual 
Financial Markets, Institutions and Risks, Volume 3, Issue 4, 2019

ISSN (online) - 2521-1242 ISSN (print) - 2521-1250

components shows that the Headline CPI is not the most worrying for policy makers, but more so 'Food and Non-Alcoholic Beverages [FNAB], Housing and Health', which is reflective of weight attached to the said components. The identified high forecast for the three components is an indication to show that policymakers need to focus policies that may seek to control future hike in inflation for the said components given the fact that the country is high importer of many of the items that makes up the FNAB component, while at the same time, the uncontrolled price hike of dollarization requirement imposed by landlords for houses / apartments and hotel accommodation is also a worrying concern. Weaknesses in government's policy implementation for good health facility is also making it quite worrying for the escalated prices levied for medical services in the country as a whole (reference to Jackson, forthcoming).

The totality of moderate inflation forecast on the headline CPI as seen in the light blue line [indicated by $I N F L$ ] in Figure 3 can prove misleading to policy makers without in-depth study of individual forecast performances. The disaggregated component forecast outlook provide an indication of the components that policy makers can focus their attention on in a bid to address future inflation hike in the country. Assessment of risks element from the Fan Charts as explained below can serve as a guide in helping policy makers to focus attention in sectors or areas where policy should be directed given their risk element.

\section{Fan Chart Communication for Disaggregated CPI Components}

Table 3. Components Forecast and Interval Estimates [2019M01 - 2019M09]

\begin{tabular}{|c|c|c|c|c|c|c|c|c|c|c|}
\hline \multirow[t]{4}{*}{ Component } & \multirow{2}{*}{\multicolumn{2}{|c|}{ Baseline Inflation }} & \multicolumn{8}{|c|}{ Confidence Intervals } \\
\hline & & & \multicolumn{4}{|l|}{$10 \%$} & \multicolumn{4}{|l|}{$90 \%$} \\
\hline & \multirow[t]{2}{*}{ 2019M01 } & \multirow[t]{2}{*}{ 2019M09 } & \multicolumn{2}{|c|}{ 2019M01 } & \multicolumn{2}{|c|}{ 2019M09 } & \multicolumn{2}{|c|}{ 2019M01 } & \multicolumn{2}{|c|}{ 2019M09 } \\
\hline & & & Lower & Upper & Lower & Upper & Lower & Upper & Lower & Upper \\
\hline Food \&Non-Alcoholic Bev. & 15.23 & 13.58 & 15.15 & 15.31 & 13.24 & 13.93 & 14.24 & 16.22 & 9.21 & 17.96 \\
\hline $\begin{array}{l}\text { Alcoholic Beverages, } \\
\text { Tobacco and Narcotics }\end{array}$ & 20.10 & 17.17 & 19.99 & 20.21 & 16.64 & 17.71 & 18.70 & 21.50 & 10.38 & 23.96 \\
\hline Clothing and Footwear & 17.78 & 16.60 & 17.68 & 17.89 & 15.86 & 17.34 & 16.48 & 19.07 & 7.21 & 25.99 \\
\hline $\begin{array}{l}\text { Housing, Water, Electricity, } \\
\text { Gas and Other Fuels }\end{array}$ & 20.04 & 9.85 & 19.90 & 20.18 & 9.28 & 10.42 & 18.28 & 21.80 & 2.64 & 17.06 \\
\hline Health & 17.58 & 13.29 & 17.45 & 17.72 & 12.94 & 13.64 & 15.91 & 19.26 & 8.84 & 17.73 \\
\hline Transport & 19.71 & 9.26 & 19.51 & 19.90 & 8.47 & 10.04 & 17.26 & 22.15 & -0.70 & 19.22 \\
\hline Communication & 11.87 & 9.89 & 11.78 & 10.97 & 9.45 & 10.34 & 10.63 & 13.11 & 4.23 & 15.56 \\
\hline Recreation and Culture & 13.44 & 10.29 & 13.34 & 13.55 & 9.23 & 9.66 & 12.15 & 14.73 & 5.61 & 14.98 \\
\hline Education & 15.36 & 8.72 & 15.23 & 15.48 & 8.26 & 9.18 & 13.76 & 16.95 & 2.81 & 14.56 \\
\hline Restaurant and Hotels & 24.22 & 19.42 & 24.04 & 24.39 & 18.88 & 19.96 & 22.03 & 26.42 & 12.60 & 26.24 \\
\hline $\begin{array}{l}\text { Miscellaneous Goods and } \\
\text { Services }\end{array}$ & 13.70 & 10.43 & 13.61 & 13.78 & 10.09 & 10.83 & 12.61 & 14.78 & 5.38 & 15.49 \\
\hline Headline CPI & 16.91 & 14.41 & 16.97 & 16.85 & 14.01 & 14.80 & 16.11 & 17.71 & 9.42 & 19.39 \\
\hline
\end{tabular}

Source: Estimation output from EVIEWS and MS Excel.

The identification of uncertainty emanating from fan charts, particularly for individual components in the CPI basket (see summary in Table 3) is essential for researchers at the BSL and more so, MPC members in their efforts to deliberate on effective policy stances. In this research, probability values [confidence bands] were used throughout to address degree of risks emanating from the forecast using uncertainty / Fan Charts as detailed in Appendix 4. These are considered a form of communication tool that inform the public and more so, MPC members about uncertainties that surround the macro-environment and from which economic agents' actions are considered critical. A well-documented risk around the Fan Charts can help policy makers and other experts in a country to deliberate on realistic policy measures that can be tailored to support a stable economic environment.

To summarise the extent of risks associated with each of the components, Table 3 above depict highlights of the degree of deviation of forecast components from the baseline, which is explained in terms of 'lower and upper limits'; this can be used to gauge policy makers' decision about measure(s) to ensure inflation revert back to a specified target for the period under review. The justification for a shorter confidence bandwidth in this study [20\%] is to take account of the fact that ARIMA methodology is a STIF approach, which according to theory (Box and Jenkins, 1976; Mordi et al, 2014) is considered very effective in forecasting outcomes for shorter time period of less than one-year duration. 
Financial Markets, Institutions and Risks, Volume 3, Issue 4, 2019

ISSN (online) - 2521-1242 ISSN (print) - 2521-1250

Fan Charts referenced in Appendix 4 have revealed realistic picture of risks emanating from the forecast as opposed to the usual restriction on the Headline CPI. This is considered a good way of assisting policy makers in their strides to developing short, medium- and long-term strategies geared towards bringing inflation to a targeted level as considered realistic by MPC members. The summary in Table 3 shows example of lower and upper bandwidths using $10 \%$ and $90 \%$ as a way of addressing risks associated with each component in the CPI basket.

The Fan Chart for headline inflation at $10 \%$ confidence interval indicate that Headline CPI is likely to be in the range of $16.97-16.88$ and $14.01-14.80$ [lower and upper bound] respectively during the observed forecast periods of 2019M01 and 2019M09. In the same token, at 90\% confidence band, the Headline CPI is projected to be in the range of $16.11-17.11$ and $9.42-19.39$ [lower and upper bound] respectively during the observed periods of 2019M01 and 2019m09. Surprisingly for Transport, the Fan Chart shows that at 90\%, there is a chance of disinflation occurring in the range of $-0.70-19.22$ [lower and upper bound] for the period 2019M09. With respect to component like Food and Non-Alcoholic Beverages, which represent the highest weight in the CPI basket, there is a 10\% confidence that inflation will fall within the range of $15.15-15.31$ and $9.21-17.96$ [lower and upper bound] respectively during the observed periods of 2019M1 and 2019M09.

5.3.1. Discourse on Risks Associated with Fan Chart Communication. In view of the downward asymmetric direction of risks associated with the Fan Charts produced for all components, there is high scope for inflation to fall, but only with effective policy actions taken by committee members, which invariably should provide critical assessment of the situations / events occurring in the domestic economy and global community by taking cognisance of financial market dynamics, for example shocks. On a similar note, policy direction must devote greater focus on high risk with components like Food and Non-Alcoholic Beverages, Housing and Health, while at the same time, not ignoring the fact that lower projected inflation forecast for other variables like Alcoholic and Tobacco [ALCTOB], Communication and Education components needs to be monitored keenly in the event of associated spill-overs or unforeseen shocks to occurrences in the domestic economy.

\section{Conclusion and Policy Recommendations}

This study has brought to the fore, the importance of applying STIF approach to forecasting disaggregated CPI components using ARIMA in support of monetary policy decision making, which is geared towards anchoring the BSL's core objective of monitoring price stability. The utilisation of STIF approach should make it possible for policy makers to judiciously factor downside and upside risks [reference to Appendix 4] as outputted from the uncertainty charts. Given the independent role of the central bank in providing policy advice to the government, there is possibility for the bank to exercise its authority as mandated in the revised BSL Act 2019 to deliberate on the most effective policy measure, which from time to time, may also involve collaboration with the fiscal authority, in this case, the Ministry of Finance $[\mathrm{MoF}]$ in a bid to anchoring its core objective of stabilising prices.

The use of disaggregated component approach is also a justified attempt to reassuring the general public and more so, policy makers (including Think-tank researchers / institutions) in Sierra Leone about the BSL's continued effort to anchoring its core mandate of stabilising prices in the country. Outcome from this research is very important given, the fact that disaggregated components from the CPI basket makes it possible for policy actions to be directed at those components that seem to have proved very risky to the overall outlook of inflation in the country. The most volatile components from the study [FNAB, Housing and Health] have revealed the importance of how policy decisions can be tailored to minimise excessive volatility in the event of shock[s], while also paying attention to policy stances that may also seek to sustain a reasonably targeted price level with components that are not considered threatening to inflationary pressure in the economy. The study has revealed the importance of correlation between high weight ascribed to components [reference to Table 1and Figure 3] and their inherent risk of projecting high inflation in the basket, which ultimately will affect headline CPI going forward into the medium- and longer-term period. Going forward, policy recommendations must seek to monitor components in the basket that drives inflation on the high end; in this case, such approach should pay premium to risks, which may emanate on account of supply or demand side threats. On this note, it is hereby recommended that resources are diverted to components within the basket that poses the highest risks in the CPI basket. In addition, continuous research efforts should be devoted using a range of econometric methodologies - incorporating VAR and FPAS in supporting policy makers' decision towards achieving single-digit inflation target. A repeat of the study to reflect changes in weights attached to 
Financial Markets, Institutions and Risks, Volume 3, Issue 4, 2019 ISSN (online) - 2521-1242 ISSN (print) - 2521-1250

components in the CPI basket will also be a motivation for future research, given the fact that economic agents' taste, expectations and also activities in the domestic economy might change with time (as seen quite recently in the Government's free tuition fees and subsidy on school buses).

\section{Acknowledgement(s)}

This is an expression of appreciation to staff in the Research Department in particular who have in various ways contributed towards the final output of this work.

\section{References}

1. Bangura, M., Caulker, E. and Pessima, S. (2012). Exchange Rate Pass-Through to Inflation in Sierra Leone: A Structural Vector Autoregressive Approach, Journal of Monetary and Economic Integration, 12(1), 93-123.

2. Bank of Sierra Leone. (2019). The Bank of Sierra Leone Act 2019. Available at: http://www.bsl.gov.sl/Bank\%20of\%20Sierra\%20Leone\%20Ascent\%202019.pdf. (Accessed: 30 July, 2019).

3. Benalal, N., Diaz del Hoyo, J.L., Landau, B., Roma, M. and Skudelny, F. (2004). To aggregatet or not to aggregate? Euro area inflation forecasting? Working Paper 374, European Central Bank.

4. Box, G. E. P., and Jenkins, G. M. (1976). Time Series Analysis: Forecasting and Control. San Francisco: Holden-Day Inc.

5. Coleman, W. O. (2007). The Cause, Costs and Compensation of Inflation, Edward Elgar.

6. Kji Espasa, A., Senra, E. and Albacete, R. (2002). Forecasting Inflation in the European Monetary Union: A disaggregated approach by countries and by sectors. European Journal of Finance, 8(4), 402-421.

7. Gordon, J.R.J. (1977). The Theory of Domestic Inflation, Amsterdam, Elsevier Science, Journal of Economic Review, 67(1), 128-34.

8. Harvey, S.K. (2012). Essays in inflation and monetary dynamics in developing countries. Doctoral Thesis, University of Nebraska, Lincoln.

9. Humphrey, T.M. (1998). Historical Origins of the Cost-Push Fallacy, Richmond, Federal Reserve Bank of Richmond Economic Quarterly, 84(3), 53-74.

10. Jackson, E.A., Jabbie, M., and Tamuke, E. (forthcoming). Dynamic effect of inflation shocks in Sierra Leone: An empirical analysis.

11. Jackson, E.A., and Tamuke, E. (forthcoming). Predicting disaggregated tourist arrivals in Sierra Leone using ARIMA Model.

12. Jackson, E.A. (2019). Systemic Health Care Failure as a Symptom of Market Failure in Sierra Leone. South African Journal of Public Health, 3(4), 72-78.

13. Jackson, E.A., and Jabbie, M. (forthcoming). Twin Deficits hypothesis as an indication of government failure in Sierra Leone: An empirical investigation (2007 to 2018).

14. Jackson, E.A., and Tamuke, E. (2019). Predicting Disaggregated Tourist Arrivals in Sierra Leone using ARIMA Model. DOI: 10.20944/preprints201909.0102.v1). Jackson.

15. E.A. and Jabbie, M. (2019). Understanding Market Failure in the Developing Country Context (Online First). In, Walter L. Filho (eds), Decent Work and Economic Growth: Encyclopedia of Sustainable Development Goals, Springer Nature Publisher. DOI: 10.1007/978-3-319-71058-7_44-1.

16. Jackson, E.A. (2018). Comparison between Static and Dynamic Forecast in Autoregressive Integrated Moving Average for Seasonally Adjusted Headline Consumer Price Index. Available at SSRN: http://dx.doi.org/10.2139/ssrn.3162606.

17. Jackson, E.A., Tamuke, E., and Sillah, A. (2018). Modelling Monthly Headline Consumer Price Index (HCPI) through Seasonal Box-Jenkins Methodology. International Journal of Sciences, 7 (1), 51-56.

18. Jackson, E.A. and Tamuke, E. (2018). Probability Forecast Using Fan Chart Analysis: A Case of the Sierra Leone Economy. Journal of Advanced Studies in Finance, 9(1), 34-44.

19. Hubrich, K. (2005). Forecasting euro area inflation: Does aggregating forecasts by HICP component improve forecast accuracy? International Journal of Forecasting, 21(1), 119-136.

20. Lim, C.H and Papi, L. (1997). An Econometric Analysis of the Determinants of Inflation in Turkey. IMF Working Paper, No. WP/97/170.

21. Mansaray-Pearce, E.A. and Liu, P. (2015). The Determinants of Inflation in Sierra Leone: A Cointegration Analysis. Journal of Economics and Sustainable Development, 6(6), 121-131.

22. Kallon, K. (1994). An econometric analysis of inflation in Sierra Leone. Journal of African Economies, 3(2): 199-230.

23. King, M. (2005). Monetary Policy: Practice Ahead of Theory. Bank of England. Mais Lecture of Economics and Finance, 3-4/2008. 
24. Mansaray-Pearce, E.A. and Liu, P. (2015). The Determinants of Inflation in Sierra Leone: A Cointegration Analysis. Journal of Economics and Sustainable Development, 6(6), 121-131.

25. Montiel, P.J. (1989). Empirical Analysis of High-Inflation Episodes in Argentina and Brazil, Washington. D. C, International Monetary Fund (IMF), Staff Papers, 36(3), 527-549.

26. Mordi, C.N.O., Adebiyi, M.A., and Adamgbe, E.T. (2012). Short Term Inflation Forecasting for Monetary Policy In Nigeria. Central Bank of Nigeria (CBN).

27. Mwenese, B., and Kwizera, A.P. (2018). Modelling and Forecasting Inflation Dynamics in Rwanda. BNR Economic Review, 13, $45-71$.

28. Prescatori, A. and S. Zaman. (2011). Macroeconomic Models, Forecasting and Policymaking. Economic Commentary No. 19. Cleveland: Federal Reserve Bank of Cleveland.

29. Rodrik, D. (1991). Premature Liberalization, Incomplete Stabilization: The Ozal Decade in Turkey, in Lessons of Economic Stabilization and its Aftermath, ed. M. Bruno, S. Fischer, E. Helpman, and N. Liviatan with L. Meridor (Cambridge, Mass, and London: MIT Press).

30. Rummel, O. (2011). A Short-term inflation forecast for South Africa, Economic Modelling and Forecasting, Pages 1-15. Centre for Central Banking Studies, Bank of England.

31. Salam, M. A., S. Salam and Feridun, M. (2006). Forecasting Inflation in Developing Nations: The Case of Pakistan, International Research Journal of Finance and Economics, EuroJournals Publishing, Inc., 3.

32. Sargent, T.J and Wallace, N. (1981). Some Unpleasant Monetarist Arithmetic", Minneapolis, Federal Reserve Bank of Minneapolis, Journal of Quarterly Review, 5, 1-17.

33. Sims, C.A. (1980). A Comparison of Interwar and Postwar Business Cycles: Monetarism Reconsidered, Amsterdam, Elsevier Science, and Journal of Economic Review, Annual Papers and Proceedings 70, 250-257.

34. Statistics Sierra Leone [SSL] (2018). Consumer Price Index December 2018 Press Release. Available at: https://www.statistics.sl/images/StatisticsSL/Documents/cpi/2018/cpi_press_release_december_2018.pdf. (Accessed: 8th February, 2019).

35. Tamuke, E., Jackson, E.A. and Sillah, A. (2018). Forecasting inflation in Sierra Leone using ARIMIA and ARIMAX: A comparative evaluation. Theoretical and Practical Research in Economic Field, 1(17), 63-74.

36. Totonchi, J. (2011). Macroeconomic Theories of Inflation. International Conference on Economics and Finance Research (IPEDR), 4, 459 - 462.

\section{Appendix 1: EVIEWS code: ARMA selection}

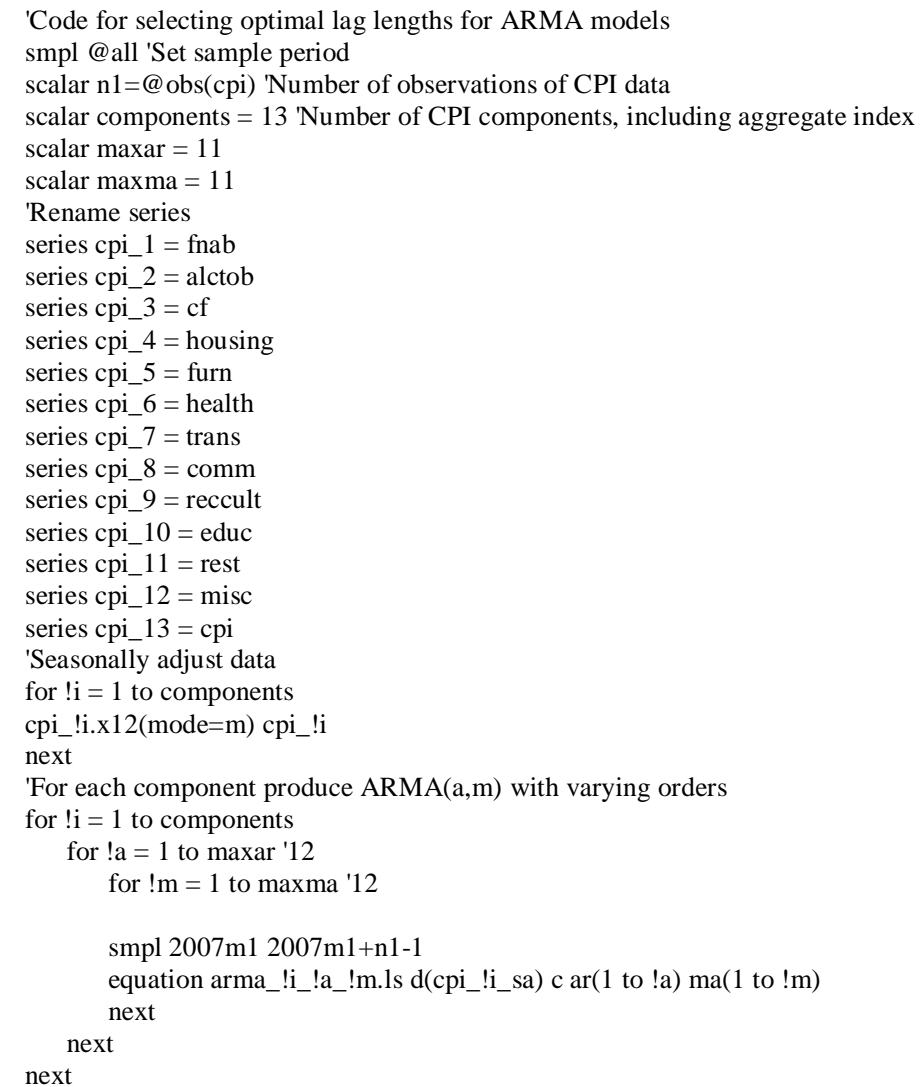


Identify the ARMA for each component with the optimal AR and MA orders according to the Akaike Information Criterion. Change to @ schwarz or @ hq for Schwarz and Hannan-Quinn criteria

for $! \mathrm{i}=1$ to components

!mininfocrit $=9999$

for $! a=1$ to maxar ' 12

for $! \mathrm{m}=1$ to maxma '12

if arma_!i_!a_!m.@aic $<$ !mininfocrit then

!besta $=$ !a

!bestm $=! \mathrm{m}$

!mininfocrit =arma_!i_!a_!m. @aic

endif

next

next

'Save the equation with the best order structure

smpl 2007m1 2007m1+n1-1

equation arma_best_!i.ls d(cpi_!i) c ar(1 to !besta) ma(1 to !bestm)

smpl 2019m01 2019m09

arma_best_!i.forecast cpi_forecast_!

next

'Show best ARMA models for selected components

for $! \mathrm{i}=1$ to 13

show arma_best_!

next

show exp(cpi_forecast_13)/exp(cpi_forecast_13(-12))*100-100

show exp(cpi_forecast_12)/exp(cpi_forecast_12(-12))*100-100

show exp(cpi_forecast_11)/exp(cpi_forecast_11(-12))*100-100

show exp(cpi_forecast_10)/exp(cpi_forecast_10(-12))*100-100

show exp(cpi_forecast_9)/exp(cpi_forecast_9(-12))*100-100

show exp(cpi_forecast_8)/exp(cpi_forecast_8(-12))*100-100

show exp(cpi_forecast_7)/exp(cpi_forecast_7(-12))*100-100

show exp(cpi_forecast_6)/exp(cpi_forecast_6(-12))*100-100

show exp(cpi_forecast_5)/exp(cpi_forecast_5(-12))*100-100

show exp(cpi_forecast_4)/exp(cpi_forecast $4(-12) * 100-100$

show $\exp ($ cpi_forecast_3)/exp(cpi_forecast_3(-12))*100-100

show exp(cpi_forecast_2)/exp(cpi_forecast_2(-12))*100-100

show exp(cpi_forecast_1)/exp(cpi_forecast_1(-12))*100-100

Appendix 2. Output for Estimated Components

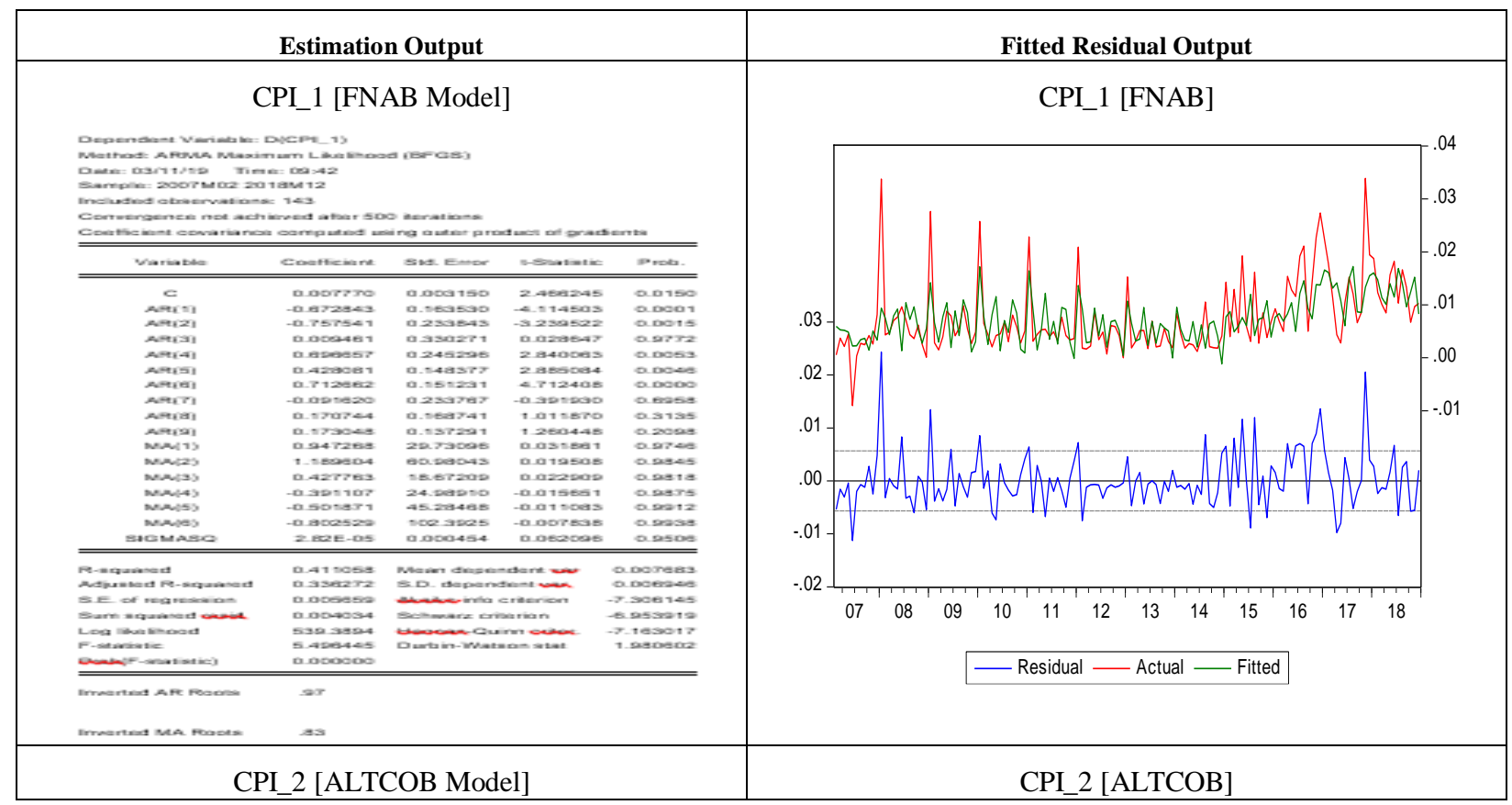




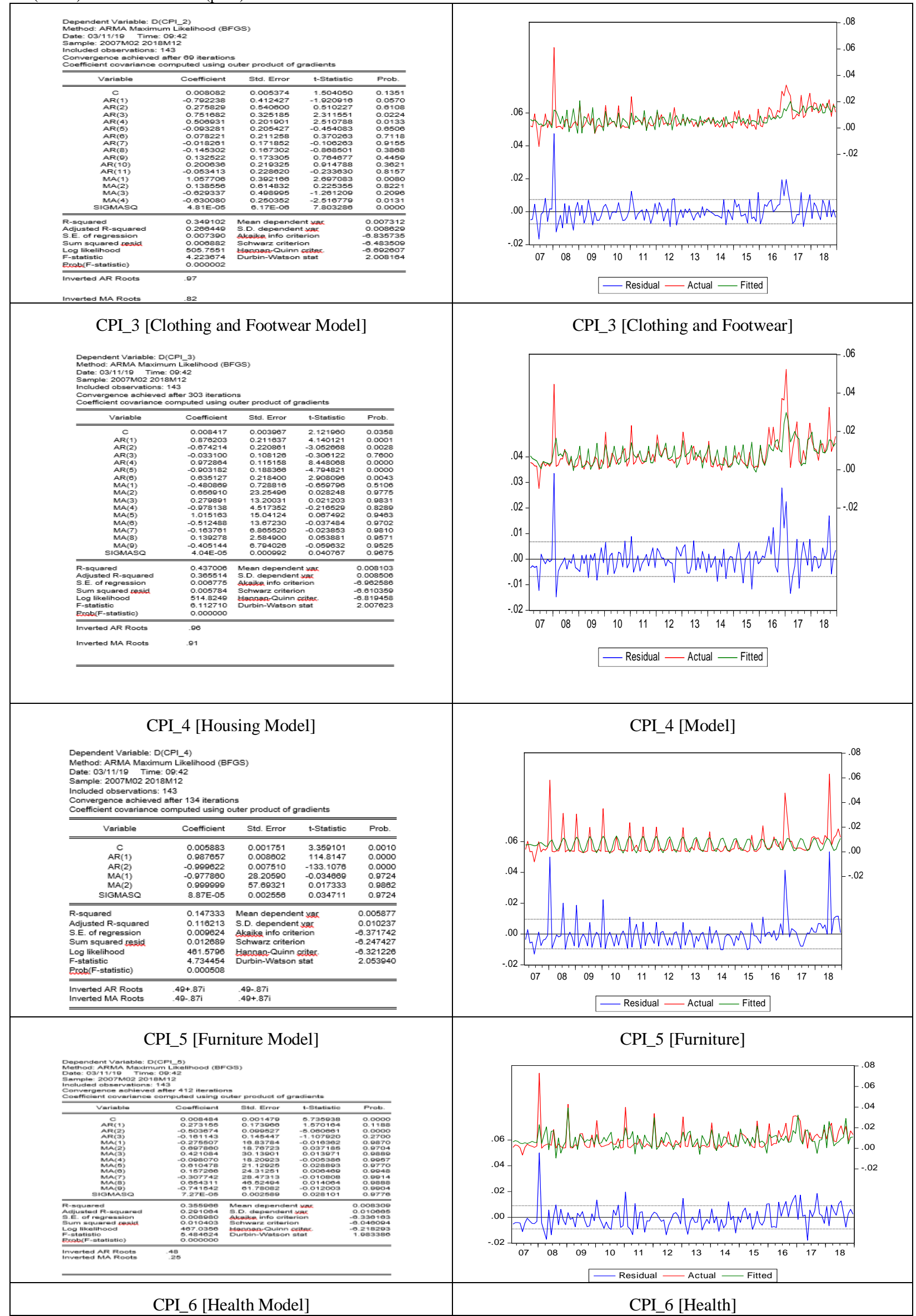




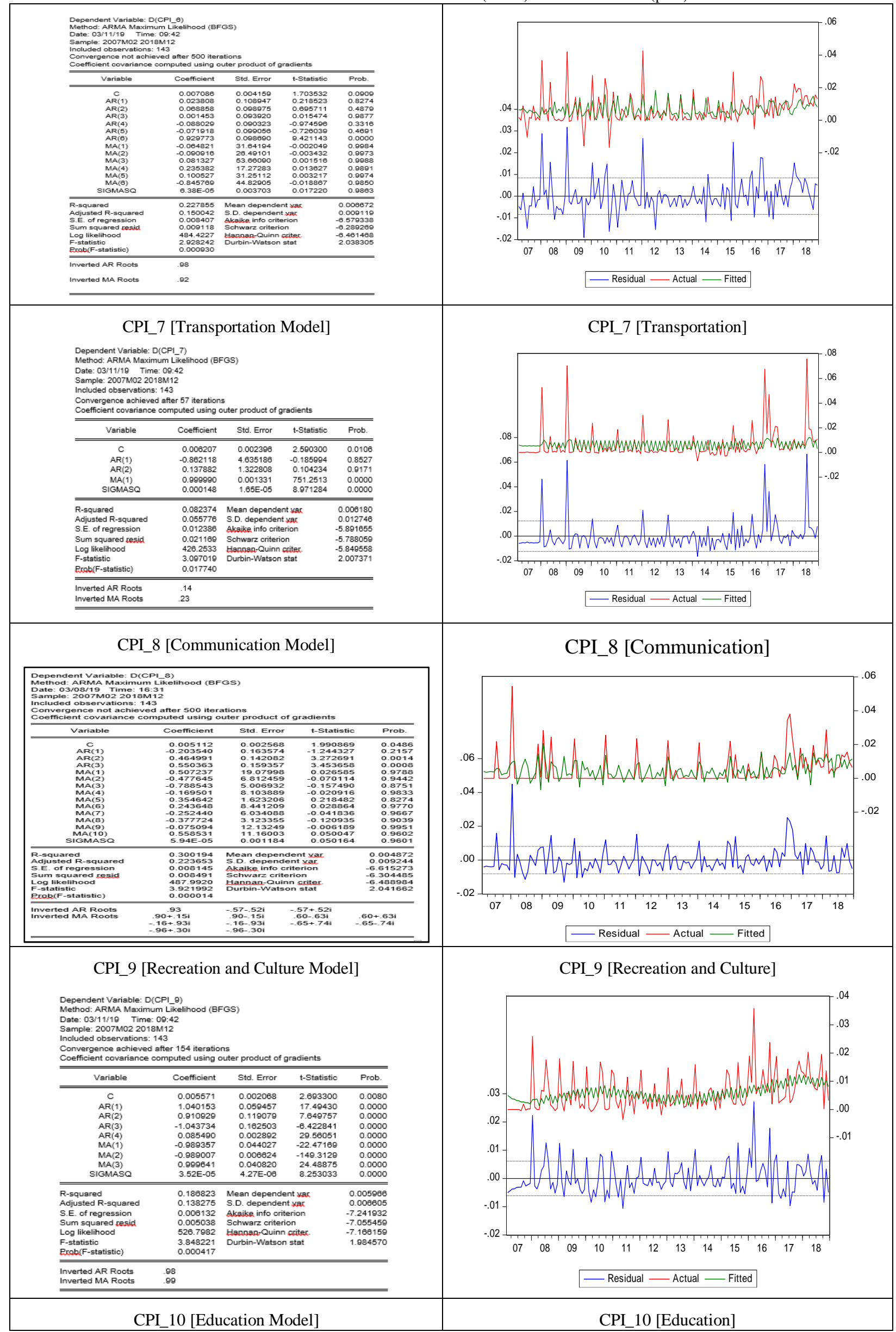




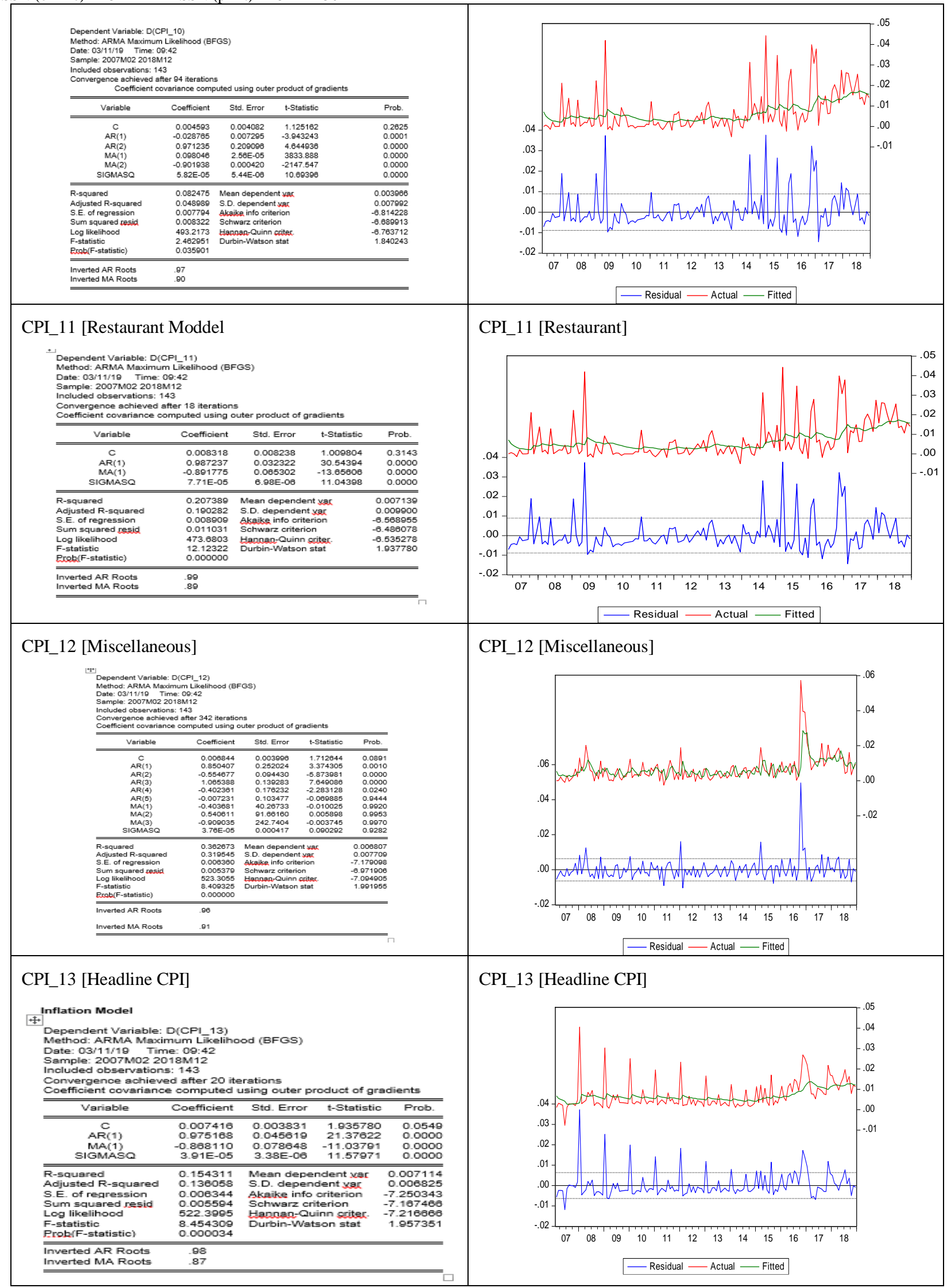

Source: Empirical Analysis in EVIEWS. 
Appendix 4. Uncertainty / Fan Charts from CPI Disaggregated Forecast Outcomes

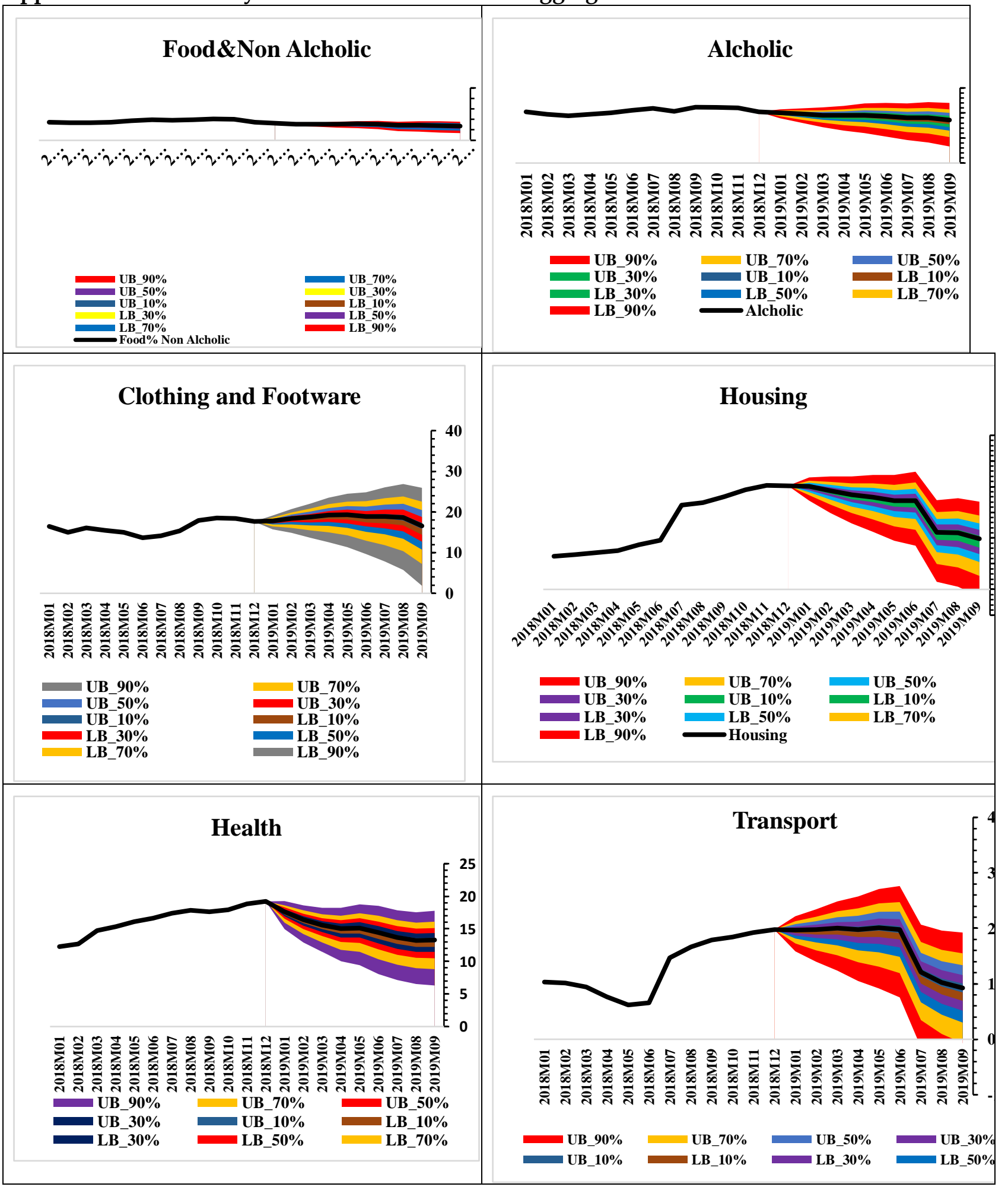




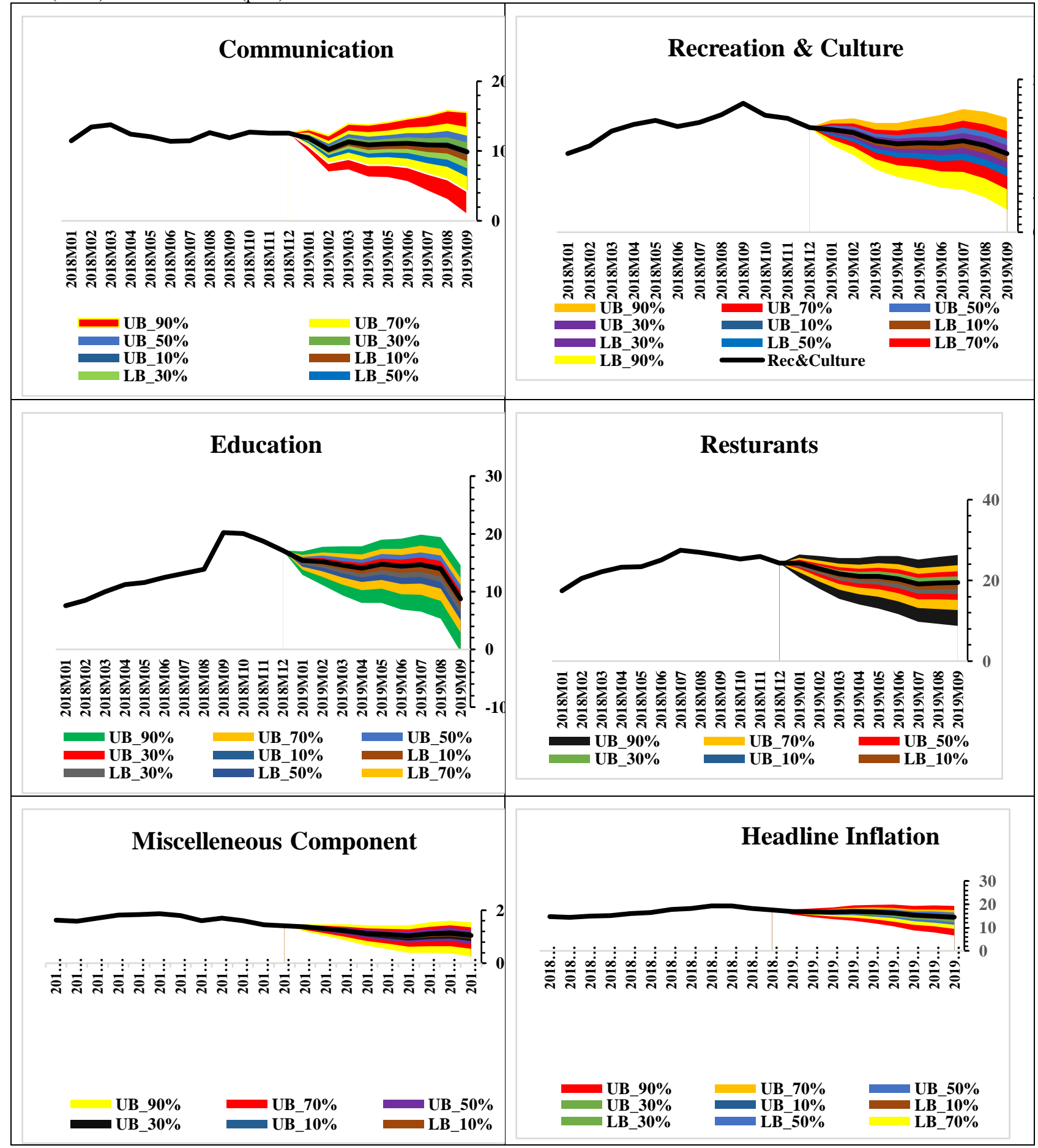

Source: Estimation Outcome. 